\title{
IDENTIFICANDO OS MODELOS DIDÁTICOS DE UM GRUPO DE PROFESSORES DE QUÍMICA
}

João Batista Santos Junior*

Maria Eunice Ribeiro Marcondes**

RESUM0: Esta investigação visa a identificar os modelos didáticos de um grupo de professores de Química de escolas públicas e propõe uma metodologia para a sua utilização como instrumento de reflexão do docente em relação às suas concepções acerca do processo de ensino e aprendizagem. Para tal, foi solicitado aos professores que respondessem a um questionário baseado nas ideias de Garcia Pérez (2000). Os resultados obtidos apontam que os professores combinam características diferentes dos modelos didáticos para formar um modelo didático eclético (GUIMARÃES, ECHEVERRÍA \& MORAES, 2006). Esses modelos ecléticos encerram características antagônicas e podem indicar a necessidade de aprofundamento da reflexão dos docentes sobre as suas concepções. É proposta uma metodologia para a utilização do instrumento de investigação do pensamento do professor.

Palavras-chave: Modelos Didáticos; Crenças Pedagógicas; Formação Profissional; Desenvolvimento Profissional.

\section{IDENTIFYING THE DIDACTIC MODELS IN A GROUP OF CHEMISTRY TEACHERS}

ABSTRACT: This study aims to identify the didactic models adopted by a group of twenty Chemistry teachers working in state schools in the state of São Paulo, Brazil. In order to obtain that information, the group were asked to answer a questionnaire based on the ideas of García Pérez (2000) whose aim was to provide the elements for the identification of the didactic model adopted by each particular teacher. The results obtained indicates that teachers combine different characteristics of the proposed didactic models and develop their own personal didactic model, classified as eclectic (GUIMARÃES, ECHEVERRÍA \& MORAES, 2006). These eclectic models combine antagonistic characteristics and may indicate the need for deeper reflection about their conceptions. This study proposes a methodology for the use of this investigative instrument of the teachers' thought.

Keywords: Didactic Models; Pedagogical Beliefs; Professional Formation. 


\section{INTRODUÇÃO}

A relação entre o pensamento do professor e a maneira como exerce a docência é tema de uma série de estudos na pesquisa em ensino (PÉREZ \& AGUADO, 2003; JÍMENEZ, 2001, 2003; SANTAELLA, 2000; ELBAZ, 1983). Esses estudos apontam para a relação intrínseca entre a prática pedagógica, o comportamento e ações do docente e as suas crenças e concepções. Estudos sobre modelos didáticos apontam que esses podem fornecer subsídios para a elucidação de aspectos imbricados no ato docente e no desenvolvimento profissional do professor (GARCIA PÉREZ, 2000; HARRES et al, 2004; GUIMARÃES, ECHEVERRÍA \& MORAES, 2006).

Esta investigação visa a identificar os modelos didáticos de um grupo de 20 professores de Química de escolas públicas de São Paulo e também propor uma maneira de utilizar esses modelos no sentido de fomentar a reflexão dos docentes sobre suas concepções, visões e ideias acerca do processo de ensino e aprendizagem. Para tal, foi desenvolvido um instrumento baseado nos pressupostos de Garcia Pérez (2000), que será detalhado na descrição da metodologia deste trabalho.

\section{MODELO DIDÁTICO PESSOAL DO PROFESSOR}

A ideia de modelo didático tem sido utilizada como uma tentativa de representar os fazeres pedagógicos dos professores (PORLÁN et al, 1996; 1997; GARCÍA PÉREZ, 2000). As tomadas de decisões, nem sempre conscientes, que permeiam o fazer pedagógico de um professor estão impregnadas por suas crenças e saberes tácitos (GIL-PÉREZ \& CARVALHO, 1995). Esse fazer pedagógico é o que se denomina modelo didático do professor.

O modelo didático é um esquema mediador entre a realidade e o pensamento do professor, uma estrutura na qual se organiza o conhecimento. Terá sempre um caráter provisório e de aproximação com uma realidade, além de ser um recurso para o desenvolvimento e fundamentação para a prática do professor (CHROBAK, 2006).

A ideia de modelo didático permite abordar (de maneira simplificada, como qualquer modelo) a complexidade da realidade escolar, ao mesmo tempo em que ajuda a propor procedimentos de intervenção nela e a fundamentar, portanto, linhas de investigação educativa e de formação dos professores (GARCÍA PÉREZ, 2000).

Porlán et al (1997) utilizam o termo "concepções epistemológicas do professor" com um significado muito próximo ao de "modelo didático", ou seja, um conjunto de ideias e formas de atuação que se relacionam com o conhecimento escolar, o seu processo de construção, ideias essas que podem se manifestar de maneira implícita ou não. 
Segundo García Pérez (2000), um modelo didático é constituído pelas crenças, pela cultura, pelas relações sociais que permeiam o processo de ensino e aprendizagem e a intencionalidade do professor em ensinar seus alunos. A construção desses modelos está baseada em cinco dimensões didáticas: qual o objetivo do ensino? O que deve ser ensinado ao aluno? Qual a relevância das ideias e interesses do aluno? Como ensinar? E como avaliar?

De acordo com essas dimensões, o pesquisador propõe quatro modelos didáticos: o tradicional, o tecnológico, o espontaneísta e o alternativo. No modelo tradicional, baseado em concepções advindas de uma perspectiva da transmissão cultural, há uma supervalorização dos conteúdos, os alunos são avaliados em relação à assimilação desses conteúdos de maneira individualizada, o papel do aluno no processo é passivo, ou seja, cabe a ele acatar e fazer o que o professor determina, não tendo maior contribuição no planejamento das atividades. Ao docente cabe, além do planejamento, controlar a disciplina da sala.

O modelo tecnológico seria uma espécie de modernização do modelo tradicional, sendo caracterizado pela incorporação de conteúdos ditos mais modernos vinculados a temáticas sociais e ambientais, pela valorização de objetivos e metas traçados no planejamento feito pelo professor. As concepções dos alunos, quando consideradas no processo, são vistas como erros conceituais; o papel do aluno é o de executar todas as atividades programadas pelo professor, que nesse modelo tem a função de direcionar o andamento das atividades programadas.

O modelo espontaneísta pode ser visto como um contraponto ao modelo tradicional, pois o aluno é tido como foco do processo, sendo valorizado o desenvolvimento de habilidades e competências. Os interesses do aluno são um componente fundamental nesse modelo didático, pois é a partir deles, juntamente com a realidade na qual estão inseridos, que o professor elabora seu planejamento. Os alunos têm um papel ativo, sendo esperado que eles sejam capazes de aprender determinados conteúdos por descoberta e compreender o contexto social em que vivem. O professor não tem um papel gerencial do processo, sendo visto como uma liderança que coordena o trabalho dos alunos.

$\mathrm{E}$, finalmente, o modelo alternativo, que representa um ensino em que o aluno vai aos poucos aumentando seus conhecimentos e consequentemente podendo atuar no mundo que o rodeia. Tanto o professor quanto o aluno exercem um papel ativo, os primeiros como investigadores de suas práticas pedagógicas e os segundos como construtores e reconstrutores de suas aprendizagens, que são alcançadas pela implantação de situações problema que exigem do aluno posturas investigativas para a sua resolução. As ideias e interesses dos alunos são considerados nesse modelo didático.

Uma síntese das características de cada modelo é apresentada na tabela 1 . 
Tabela 1-Características dos modelos didáticos segundo Garcia Pérez (2000)

\begin{tabular}{|c|c|c|c|c|}
\hline Dimensão didática & Tradicional & Tecnológico & Espontaneísta & Alternativo \\
\hline $\begin{array}{l}\text { 1- Qual o objetivo do } \\
\text { ensino? }\end{array}$ & $\begin{array}{c}\text { Transmitir ao aluno } \\
\text { conteúdos já } \\
\text { consagrados da cultura } \\
\text { vigente. }\end{array}$ & $\begin{array}{l}\text { Proporcionar ao aluno } \\
\text { uma formação moderna } \\
\text { e eficiente. }\end{array}$ & $\begin{array}{l}\text { Capacitar } 0 \text { aluno para } \\
\text { que possa compreender } \\
\text { sua realidade. }\end{array}$ & $\begin{array}{l}\text { Proporcionar ao aluno } \\
\text { uma compreensão } \\
\text { cada vez mais complexa } \\
\text { do mundo e de como } \\
\text { atuar nesse. }\end{array}$ \\
\hline $\begin{array}{l}\text { 2. } 0 \text { que deve ser } \\
\text { ensinado ao aluno? }\end{array}$ & $\begin{array}{c}\text { Conteúdos } \\
\text { disciplinares, conceitos } \\
\text { específicos. }\end{array}$ & $\begin{array}{c}\text { Conteúdos que } \\
\text { propiciem uma } \\
\text { formação cultural atual, } \\
\text { conhecimentos não } \\
\text { somente disciplinares. }\end{array}$ & $\begin{array}{c}\text { Conteúdos presentes na } \\
\text { realidade imediata do } \\
\text { aluno. }\end{array}$ & $\begin{array}{l}\text { Conhecimentos interdis- } \\
\text { ciplinares, o enfoque } \\
\text { está no contexto social. }\end{array}$ \\
\hline $\begin{array}{l}\text { 3- Qual a relevância } \\
\text { das ideias e interess- } \\
\text { es do aluno? }\end{array}$ & Não considera. & $\begin{array}{l}\text { Quando considera as } \\
\text { concepções, essas } \\
\text { são vistas como erros } \\
\text { conceituais. }\end{array}$ & $\begin{array}{l}\text { Considera apenas os } \\
\text { interesses imediatos do } \\
\text { aluno. }\end{array}$ & $\begin{array}{c}\text { Considera os interesses } \\
\text { e as concepções do } \\
\text { aluno. }\end{array}$ \\
\hline 4- Como ensinar? & $\begin{array}{c}\text { Metodologia baseada } \\
\text { na transmissão cultural. }\end{array}$ & $\begin{array}{l}\text { Metodologia baseada } \\
\text { na transmissão cultural } \\
\text { e descoberta dirigida. }\end{array}$ & $\begin{array}{l}\text { Metodologia baseada } \\
\text { no protagonismo do } \\
\text { aluno, que vai desco- } \\
\text { brindo o conhecimento. }\end{array}$ & $\begin{array}{l}\text { Baseada na ideia da } \\
\text { investigação escolar, } 0 \\
\text { aluno constrói e recon- } \\
\text { strói o conhecimento. }\end{array}$ \\
\hline 5-Como avaliar? & $\begin{array}{c}\text { Avaliação centrada nos } \\
\text { conteúdos transmitidos, } \\
\text { realizada por meio de } \\
\text { provas formais. }\end{array}$ & $\begin{array}{l}\text { Avaliação centrada nos } \\
\text { conteúdos transmitidos, } \\
\text { porém, em alguns } \\
\text { momentos, pode aferir } \\
\text { o processo. }\end{array}$ & $\begin{array}{l}\text { Avaliação centrada nas } \\
\text { habilidades e } \\
\text { competências; utiliza } \\
\text { a observação e a } \\
\text { produção individual e } \\
\text { coletiva do aluno. }\end{array}$ & $\begin{array}{l}\text { Avaliação centrada no } \\
\text { desenvolvimento do } \\
\text { aluno e na atuação do } \\
\text { professor; utiliza } \\
\text { múltiplos instrumentos } \\
\text { individuais e coletivos. }\end{array}$ \\
\hline
\end{tabular}

\section{METODOLOGIA}

O público-alvo desta pesquisa foi um grupo de 20 professores de Química com experiências profissionais muito variadas. A tabela 2 apresenta o perfil de cada professor pesquisado.

Tabela 2- Caracterização dos professores pesquisados

\begin{tabular}{c|c|c|c} 
Professor & Tempo de docência/anos & Formação & Idade \\
\hline P01 & 6 & Engenharia química/pós-graduação & 30 \\
\hline P02 & 8 & Bacharelado e licenciatura & 31 \\
\hline P03 & 22 & Licenciatura & 47 \\
\hline P04 & 23 & Licenciatura & 47 \\
\hline P05 & 8 & Licenciatura & 31 \\
\hline P06 & 6 & Licenciatura & 29 \\
\hline P07 & 15 & Licenciatura & 39 \\
\hline P08 & 11 & Bacharelado e licenciatura & 50 \\
\hline P09 & 13 & Licenciatura & 34 \\
\hline P10 & 10 & Licenciatura & 26 \\
\hline P11 & 4 & Engenharia química/pós- graduação & 44 \\
\hline P12 & 13 & Bacharelado e licenciatura & 59 \\
\hline P13 & 20 & Licenciatura & 38 \\
\hline P14 & 13 & Licenciatura & 25 \\
\hline P15 & 3 & Licenciatura/pós-graduação & 33 \\
\hline P16 & 10 & Licenciatura & 52 \\
\hline P17 & 22 & Licenciatura & 22 \\
\hline P18 & 4 & Licenciatura & 39 \\
\hline P19 & 12 & Química industrial e licenciatura & 26
\end{tabular}


Esses docentes participavam de um curso de formação continuada no IQ-USP no segundo semestre de 2007, no qual os autores eram formadores. Após dois meses de atividades, os autores desta investigação julgaram que os docentes já se sentiam à vontade com a rotina do curso e solicitaram a um grupo de cursistas que respondessem ao questionário e o devolvessem respondido na aula seguinte. Vinte professores entregaram o instrumento respondido conforme solicitado.

$\mathrm{O}$ instrumento consistia de uma pergunta-chave correspondente a cada uma das dimensões didáticas e para cada uma delas existiam quatro proposições características de cada um dos modelos didáticos propostos por Garcia Pérez (2000). A primeira entre as quatro proposições diz respeito ao modelo tradicional; a segunda referia-se ao modelo tecnicista; a terceira ao modelo espontaneísta e a quarta ao modelo alternativo.

O professor deveria atribuir um valor para cada proposição seguindo o critério ( 0 , completa rejeição; 3 completa aceitação; os valores 1 e 2 seriam intermediários entre a rejeição e a aceitação).

Esse questionário, que é apresentado na figura 1, foi aplicado inicialmente com alunos de licenciatura de um curso de Química e de pós-graduação de um programa de ensino de Ciências, com o intuito de verificar a funcionalidade do instrumento e a adequação das proposições para caracterizar os modelos didáticos correspondentes.

Feita essa comprovação, esse instrumento sem alterações foi utilizado nesta investigação e também como instrumento para diagnosticar a reestruturação no pensamento de um grupo de professores de Química que participaram de um grupo colaborativo cujo objetivo era a problematização das suas respectivas práticas pedagógicas por um período de um semestre (SANTOS, 2009).

Figura 1- Instrumento para identificar os modelos didáticos do professor

\section{Professor, por favor, atribua um valor de importância para cada uma das proposições relacionadas na tabela no que diz respeito a sua concordância com elas em relação às suas aulas. $0=$ nenhuma importância, 1, 2, 3= máxima importância.}

Qual é o meu maior objetivo ao ensinar Química para os meus alunos? Para que meu aluno possa se tornar um indivíduo dotado da cultura vigente. Para que meu aluno tenha uma formação eficiente e moderna, ou seja, esteja inserido no mundo tecnológico, no qual todos nós precisamos conviver.

Para que meu aluno se torne um cidadão crítico, ético e atuante no mundo em que vive. Para que meu aluno possa enriquecendo progressivamente seus conhecimentos e vá aos poucos conseguindo fazer leituras cada vez mais complexas do mundo em que vive.

Que conteúdos de Química devo ensinar aos meus alunos? Uma síntese dos conceitos químicos mais importantes. Uma síntese dos conceitos químicos mais importantes, combinados com aplicaç̃os tecnológicas desses conceitos. Uma síntese dos conceitos químicos mais importantes, combinados com aplicações tecnológicas desses conceitos. Conhecimentos que permitam a integração nos níveis científicos, social, histórico e ambiental. 
Os interesses não precisam ser considerados, as concepções sim. Caso essas concepções sejam erradas devem, com Valor o ensino, ser substituídas pelo aluno por concepções mais próximas das científicas.

As concepções não precisam ser consideradas, os interesses sim, pois dessa forma 0 estudo de Química pode ser mais atraente e significativo para 0 aluno.

As concepções e os interesses devem nortear a escolha dos conteúdos que irão ser trabalhados.

Como devo ensinar Química aos meus alunos?

Como professor, devo estar apto a transmitir conhecimento ao meu aluno e manter uma ordem mínima necessária.Para que seja possível 0 trabalho, 0 aluno, por sua vez, se fizer a sua parte, ou seja, prestar atenção às aulas, fizer as atividades e se esforçar um pouco, poderá aprender Química com sucesso.

Como professor, devo combinar aulas expositivas com aulas práticas, usando todos os recursos didáticos de que disponho e atuar dentro da sala como um administrador das atividades. 0 aluno, por sua vez, deve fazer as atividades propostas.

Como professor, devo propor atividades que estimulem a capacidade de meu aluno de analisar, julgar, criticar e exercer a sua cidadania, além, é claro, de aprender Química. Devo atuar dentro da sala como um coordenador, 0 aluno é 0 centro do processo de ensino-aprendizagem.

Como professor, devo propor situações problema para o meu aluno e atividades que permitam ao aluno ir resolvendo esse problema. Dentro da sala devo atuar como um mediador e um investigador no processo de ensino-aprendizagem. 0 aluno tem um papel ativo na construção e reconstrução do seu conhecimento.

Como deve ser a minha forma de avaliar os meus alunos?

A minha avaliação deve cobrir o conteúdo trabalhado e com instrumentos individuais do tipo provas e listas de exercícios preferencialmente, buscando levantar 0 conhecimento adquirido pelo aluno durante o período.

A minha avaliação deve cobrir o conteúdo trabalhado, os instrumentos não precisam ser especificamente individualizados, mas precisam me dar dados confiáveis para medir a aprendizagem e analisar o processo de ensino-aprendizagem.

A minha avaliação deve privilegiar a mudança de atitude do meu aluno, as habilidades e competências construídas no processo de ensino-aprendizagem. Por isso a minha observação é um fator importantíssimo.

A minha avaliação deve privilegiar a evolução dos conhecimentos do meu aluno no processo de ensino-aprendizagem. Posso utilizar instrumentos individualizados ou coletivos, a minha observação. Essa avaliação também me orienta a fazer as modificações necessárias no processo visando a um melhor rendimento dos meus alunos.

\section{RESULTADOS E DISCUSSÃO}

Foi arbitrado neste trabalho que, sempre que o professor atribuísse os valores 2 ou 3 para uma dada proposição do instrumento, ele estaria aceitando essa característica na composição de seu modelo didático pessoal. De acordo com a aceitação do docente, foi elaborada uma representação em que as áreas coloridas correspondem às características aceitas por esse professor, ou seja, aquelas em que o docente atribuiu o valor 2 ou 3.

Esta representação é apresentada pela figura 2. Vale ressaltar que a dimensão 1 corresponde aos objetivos do ensino; a dimensão 2 refere-se aos conteúdos; a dimensão 3 ao papel das ideias e interesses dos alunos; a dimensão 4 à metodologia e a dimensão 5 à avaliação. 
Figura 2 - Organização dos professores de acordo com os seus modelos didáticos ecléticos e visão do processo de ensino e aprendizagem

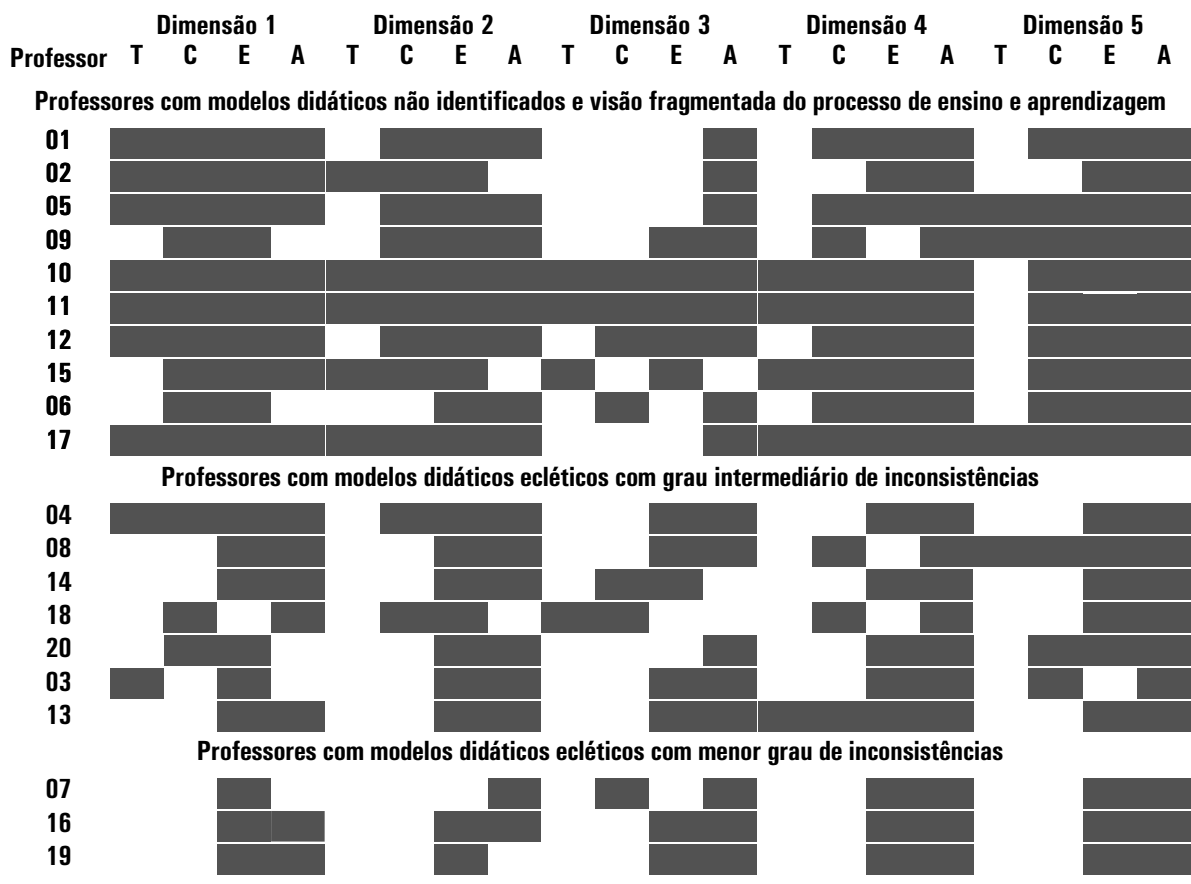

Legenda: T tradicional, C tecnicista, E espontaneísta, A alternativo.

Os resultados obtidos corroboram as observações de Guimarães, Echeverría e Moraes (2006) sobre o fato de que os professores se apropriam de características de diferentes modelos didáticos propostos por Garcia Pérez (2000), para compor um modelo didático pessoal, chamado pelos pesquisadores de eclético. Os modelos didáticos ecléticos diagnosticados aqui serão abordados na parte final desta discussão.

Assume-se que os modelos didáticos tradicional e tecnicista têm em comum a tendência para a transmissão cultural dos conteúdos e que os modelos espontaneísta e alternativo estão alinhados à visão construtivista do processo de ensino e à aprendizagem. Nesta perspectiva, as aceitações declaradas no instrumento foram tidas como consistentes sempre que agregassem características de modelos didáticos de mesma orientação pedagógica.

Assim, um modelo didático eclético formado pelas características dos modelos tradicional e tecnicista TC ou pelas características dos modelos espontaneísta e alternativo EA foi considerado como consistente. Em contrapartida, um modelo eclético formado, por exemplo, pelas características dos modelos tradicional e espontaneísta TE foi considerado inconsistente.

Nessa linha de raciocínio, o modelo didático eclético do tipo TCEA é mais inconsistente que o do tipo CEA, porque, enquanto o primeiro é compos- 
to pelas características dos quatro modelos, o segundo é formado pelas características de três desses modelos didáticos. O que pode evidenciar que as características relativas ao modelo didático tradicional $\mathbf{T}$ não condizem com as concepções e ideias do professor em que o modelo eclético do tipo CEA foi identificado. Uma abordagem diferente para analisar-se o modelo eclético TCEA será feita no momento em que esses modelos forem discutidos mais detidamente.

A visão do professor do processo de ensino e aprendizagem também pode ser investigada por essa metodologia. Pode-se inferir que, se o docente tem visão coesa do processo de ensino e aprendizagem, apresentará modelos ecléticos parecidos em todas as dimensões didáticas analisadas. Isso porque todas estão relacionadas.

Se, no entanto, o professor tiver uma visão fragmentada do processo de ensino e aprendizagem, ele poderá possuir modelos ecléticos muito diferentes em cada uma das cinco dimensões didáticas. Tal fato evidencia que esse professor ainda não é capaz de perceber o processo como um todo.

Uma constatação chamou a atenção: as características do modelo didático tradicional $\mathbf{T}$ foram as mais rejeitadas pelos professores. Talvez, esse seja mais um indício de que essa visão do processo de ensino e aprendizagem vem sendo paulatinamente superada pelos professores.

Dessa forma, foi possível organizar os docentes em três subgrupos tendo-se como base a consistência das características aceitas em seus respectivos modelos ecléticos e pela coesão diagnosticada de suas visões do processo de ensino- aprendizagem.

O primeiro subgrupo era formado por dez professores $(1,2,5,6,9$, $10,11,12,15$ e 17) e se caracterizava pela aceitação simultânea de muitas características antagônicas. Devido às muitas inconsistências detectadas, não há como identificar um modelo didático capaz de representar esses docentes.

A visão do processo de ensino e aprendizagem dos docentes desse subgrupo foi considerada como fragmentada, tendo em vista que os modelos didáticos ecléticos desses docentes variavam muito de uma dada dimensão didática para outra. Dentro dessa perspectiva, pode-se inferir com base nas declarações dadas que, para esses docentes, as diferenças entre as características dos modelos didáticos propostos por Garcia Pérez (2000) não são perceptíveis.

Pode-se supor que esses professores não superaram a visão tradicional de pensar o ensino embora admitam ou conheçam os pressupostos de abordagens centradas na participação ativa dos alunos. Tais considerações podem ter implicações na formulação de cursos de formação continuada, pois isso significa que o formador deve considerar os diferentes saberes e crenças pedagógicas que os docentes podem apresentar.

Um segundo grupo, formado por sete professores $(3,4,8,13,14,18$ e 20), foi caracterizado por apresentar menos modelos ecléticos considerados como inconsistentes e visão do processo um pouco mais organizada que o primeiro subgrupo. Por tratar-se de uma organização arbitrária, alguns casos dessa 
classificação podem gerar certa controvérsia. Um exemplo é o P4: se fosse considerado apenas o número de modelos ecléticos, ele poderia ser agrupado no primeiro subgrupo, porém, ao analisar os modelos apresentados nas dimensões didáticas, percebe-se que esse docente não tem visão do processo tão fragmentada quanto os professores do primeiro subgrupo nas dimensões 3, 4 e 5 . Ele tem modelos didáticos ecléticos do tipo EA, diagnosticado como um modelo de menor grau de inconsistência.

Pode-se inferir que os professores desse subgrupo apresentam um movimento em direção a concepções mais elaboradas, refletido pela seleção de proposições que apontam para os modelos espontaneísta e alternativo e rejeição daquelas que representam ideias mais tradicionais de ensino. Ainda se notam incoerências e contradições, típicas de um processo de reflexões e transformações.

O último subgrupo, composto por três professores, se caracteriza por ter modelos ecléticos com menos inconsistências e visão do processo de ensino e aprendizagem mais integrada. Em relação aos docentes desse subgrupo, fica evidente a manifestação de concepções concordantes em parte com os modelos espontaneísta e alternativo, EA.

Deve-se considerar, como citam Garcia e Porlán (2000), que os saberes profissionais que os professores apresentam são formulados em uma dimensão evolutiva e progressiva, mediante um processo aberto de reorganização contínua de seus sistemas de ideias. Assim, os modelos didáticos pessoais representam momentos de suas reflexões e práticas.

Em relação às dimensões didáticas é possível identificar aquelas em que se concentra o maior número de professores com modelos ecléticos tidos como mais inconsistentes. A dimensão 3, que diz respeito ao papel das ideias e interesses dos alunos, foi a dimensão em que apareceu o menor número de docentes com modelos didáticos ecléticos (15 no total de 20 docentes) e também onde apareceu o maior número de professores (5) com modelos didáticos conforme as ideias de Garcia Pérez (2000).

O maior número de rejeições às proposições apresentadas (valores 0 e 1) também se encontra na dimensão 3. Uma análise das proposições rejeitadas corrobora a ideia de os professores considerarem as concepções dos alunos em suas decisões sobre o ensino, pois não concordam com perspectivas que desconsideram ou minimizam tais concepções e interesses dos alunos.

A dimensão 1, que diz respeito aos objetivos de ensinar Química, é a que apresentou menor grau de convergência na escolha das proposições aceitas. Oito professores se inserem no modelo eclético do tipo TCEA, característico daquele docente que não consegue perceber as diferenças entre as visões do processo de ensino e aprendizagem, o que permite inferir indefinição a respeito de seus objetivos para ensinar Química. Para os outros 11 professores foram diagnosticados objetivos mais bem definidos para o ensino.

Chama a atenção que o objetivo relacionado ao modelo tradicional, de que o aluno domine a cultural vigente, foi rejeitado pela maioria dos docentes do 
grupo, enquanto que o objetivo relativo ao modelo espontaneísta, de que o aluno se torne um cidadão crítico, foi rejeitado apenas por um professor. Esses dados parecem revelar que o discurso oficial, presente, por exemplo, nas diretrizes curriculares nacionais (DCN, BRASIL, 1999) e nos parâmetros curriculares nacionais (PCN, BRASIL, 1999), está sendo incorporado, no aspecto analisado, ao discurso dos professores.

Deve-se considerar também que essa perspectiva de ensino voltado para a cidadania, independentemente de suas diferentes vertentes (SANTOS \& MORTIMER, 2001), vem sendo amplamente divulgada em meios de comunicação e, na Química em particular, nas revistas da área, em encontros de ensino, em cursos de formação continuada.

A análise da dimensão 2, o que deve ser ensinado de Química, apoia essas considerações. A grande maioria dos professores (16) rejeita ou considera pouco importante que seu ensino apresente uma síntese dos conceitos químicos mais relevantes, dando preferência a conceitos que permitam o estabelecimento de relações com a tecnologia, o dia a dia do aluno e ainda com aspectos sociais, ambientais e históricos.

Tais relações podem ter diferentes significados, como mostra o estudo de Domingues et al (1995, apud GUIMARÃES, ECHEVERRÍA \& MORAES, 2006), sobre os currículos de Ciências, em que a inclusão do cotidiano do aluno no ensino vai desde situações vividas efetivamente por ele, em seu ambiente, como situações decorrentes de um contexto mais amplo da sociedade. Não se trata de avaliar quais perspectivas o professor está enfocando, mas de enfatizar que o docente prioriza em seu discurso a contextualização do conhecimento químico em detrimento do tratamento apenas conceitual.

Com relação à dimensão 4, que enfoca as estratégias de ensino, cinco professores apresentaram o modelo eclético do tipo TCEA, revelando, mais uma vez, uma indefinição em sua visão do processo de ensino e aprendizagem. Nessa dimensão, também, a proposição que diz respeito ao modelo tradicional foi rejeitada ou considerada pouco importante por 15 professores.

As aulas ditas expositivas parecem não representar a prática desses professores, embora seja essa a prática escolar hegemônica nas aulas de Química no Ensino Médio. Pode-se considerar que os professores estão em um momento de transição, pois parecem incorporar o discurso tanto dos PCN quanto da comunidade dos pesquisadores de ensino de Ciências (SCHNETZLER, 2004), embora suas aulas ainda possam estar baseadas no modelo de transmissão cultural.

Os modelos identificados na dimensão didática 5 permitem inferir que, no que concerne a avaliar os alunos, os professores pesquisados parecem ter incorporado ideias alinhadas à visão construtivista do ensino. Todos os docentes aceitaram as características dos modelos didáticos com essa tendência. Contudo, 12 professores aceitaram também as características do modelo tecnicista. 
Fica evidente que os modelos didáticos ecléticos se aproximam mais do fazer pedagógico do grupo pesquisado que os modelos didáticos propostos por Garcia Pérez (2000). Por essa razão é preciso investigar esse tipo de modelo didático com maior ênfase.

A natureza eclética desses modelos pode ser um indicativo de que o docente precisa aprofundar a reflexão sobre a sua visão do processo de ensino e aprendizagem, sobre as suas crenças e concepções. Tal observação se deve ao fato de que algumas das características dos modelos didáticos propostos por Garcia Pérez (2000) são antagônicas dentro da mesma dimensão didática.

Dois tipos de modelos ecléticos chamaram a atenção: o TCEA, caracterizado pela aceitação das características dos quatro modelos didáticos propostos por Garcia Pérez (2000); e o modelo eclético do tipo EA, formado, respectivamente, pelas características dos modelos didáticos espontaneísta e alternativo.

Em relação ao primeiro modelo eclético, devido ao seu alto grau de inconsistências, pode-se considerar que ele indica na verdade a ausência de um modelo didático de referência para o docente e, por isso, talvez fosse mais sensato não qualificá-lo como um modelo eclético. Assim, os professores do subgrupo 1 teriam em comum a necessidade de intervenções que fossem capazes de auxiliá-los a refletir com maior profundidade sobre suas concepções e visões acerca do processo de ensino e aprendizagem.

O modelo eclético do tipo EA, por sua vez, parece indicar uma tendência pedagógica ou talvez a convergência de visões e concepções sobre o processo. Embora haja diferenças significativas entre os dois modelos didáticos que formam esse tipo de modelo eclético, é preciso salientar que o fato de considerarem, mesmo que em diferentes perspectivas, a participação efetiva do aluno no processo de ensino-aprendizagem e o estabelecimento de relações entre os conteúdos científicos e o cotidiano e a sociedade, aspectos muito enfatizados nos PCN e na comunidade dos educadores químicos, provocou identificação dos professores com os pressupostos desses modelos.

Não se pode deixar de considerar, como aponta Porlán (1998), que a perspectiva de enfatizar conteúdos próximos aos interesses e às experiências dos alunos, embora possa representar um avanço ao modelo didático tradicional, centrado na transmissão dos conteúdos, pode significar uma simplificação no tratamento conceitual, pois os professores, ao valorizarem tais aproximações, podem considerar apenas superficialmente as concepções prévias que os alunos têm.

Percebe-se nos professores do subgrupo 2, que se caracterizam por ter visão sobre o processo de ensino e aprendizagem um pouco mais que os docentes do subgrupo 1, uma certa tendência em direção ao modelo eclético do tipo EA. Apesar da existência de algumas inconsistências, essa tendência em graus diferentes é apontada na representação da figura 2.

O modelo eclético EA é o que melhor identifica os professores do subgrupo 3. Esses docentes têm visão do processo de ensino e aprendizagem 
mais uniforme e coesa. Talvez por essa razão deva-se considerar esse modelo eclético como uma concepção de ensino e aprendizagem, sendo então EA um modelo didático que represente os docentes aqui pesquisados.

Finalizando essa análise, um dos objetivos dessa investigação, que era a identificação dos modelos didáticos dos docentes pesquisados, pode-se dizer nesse sentido que, em três professores (7, 16 e 19) foi identificado como modelo que representa o seu pensamento sobre o processo de ensino e aprendizagem o modelo eclético do tipo EA. Para dez professores (1, 2, 5, 6, 9, 10, 11, 12, 15 e 17), não foi possível identificar um modelo didático capaz de ser uma referência para representar suas ideias e concepções sobre o ensino. E sete professores $(3,4,8,13,14,18$ e 20$)$ aparentam um estado em que a tendência para o modelo eclético EA parece estar se consolidando em suas respectivas visões e concepções sobre o ensino e aprendizagem.

Conclui-se que os modelos didáticos conforme a proposição de Garcia Pérez (2000) não são capazes de representar o grupo de professores aqui pesquisado. Nesta perspectiva, o modelo eclético EA parece ser mais adequado para essa finalidade. Outro ponto que chama a atenção é que, para a metade dos professores aqui pesquisados, foi impossível detectar um modelo didático que servisse como referência. Tal fato pode estar relacionado a uma limitação do instrumento, mas pode também indicar que esse grupo precisa de alguma maneira refletir sobre suas concepções e ideias.

Esse diagnóstico se relaciona com o segundo objetivo desta investigação: propor uma metodologia em que a explicitação desses modelos didáticos pudesse servir de subsídio para a reflexão do docente. Instrumentos com natureza capaz de explicitar o pensamento do professor são úteis porque podem tornar esse pensamento em objeto de análise. Essa é uma situação que não é comum entre os docentes, quer seja nas suas rotinas escolares, quer seja em cursos de formação continuada.

Nesse sentido, ao notar que existem inconsistências em relação aos modelos didáticos identificados nas declarações dos docentes, pode-se propor situações em que essas inconsistências possam ser resolvidas, tornando a visão sobre o ensino e a aprendizagem desses professores mais coesa e consistente.

\section{CONSIDERAC̣ÕES FINAIS}

Os modelos didáticos propostos por Garcia Pérez (2000) parecem não ser suficientes para representar o fazer pedagógico dos professores aqui investigados. Essa impossibilidade talvez possa ser justificada pelo fato de esses modelos didáticos terem sido concebidos a partir da realidade de docentes de outro país. Nessa perspectiva, é possível que o modelo eclético do tipo EA seja um modelo capaz de representar os professores brasileiros? Com os elementos fornecidos neste trabalho, não há como responder a essa questão, porém, fica evi- 
dente que o estudo sobre os modelos didáticos dos professores brasileiros é um terreno fecundo para mais estudos.

O pensamento do professor é uma estrutura complexa. As crenças e concepções pedagógicas presentes nessa estrutura são apontadas como componentes fundamentais na formação do professor, na sua prática e no seu desenvolvimento profissional (PORLÁN et al, 1996; 1997; FURIÓ, 1994; PEME-ARANEGA, 1999; 2001). Por essa razão estudos nessa área podem trazer informações preciosas para a melhoria do ensino e aprendizagem.

$\mathrm{O}$ instrumento aqui desenvolvido foi utilizado inicialmente para identificar os modelos didáticos do grupo pesquisado. Pela natureza também complexa de um modelo didático em que estão imbricados elementos como as concepções e crenças pedagógicas do docente, o contexto em que exerce a docência e a sua visão do processo de ensino e aprendizagem.

Um instrumento capaz de explicitar esses elementos e torná-los objeto de reflexão e análise poderia ser utilizado na formação inicial, com o intuito de fazer com que os futuros docentes explicitem esses elementos e possam refletir a respeito. Essa prática poderia, ao menos em tese, dificultar a perpetuação de ideias e procedimentos tidos como tradicionais e que são incorporados pelos licenciandos.

É possível explorar a natureza dos modelos ecléticos no que diz respeito à consistência das características que os formam. Também é possível perceber se o docente tem visão fragmentada do processo de ensino e aprendizagem e, ainda, as dimensões didáticas estão os modelos didáticos ecléticos mais inconsistentes. Por esse viés, é possível utilizar os modelos didáticos ecléticos como subsídio para fomentar a reflexão do professor sobre o seu pensamento.

Outra utilização para um instrumento como o criado aqui seria em cursos de formação continuada. Neste sentido o instrumento poderia ser aplicado no inicio e no fim do projeto. Dessa maneira seria possível perceber se os conteúdos e atividades programados para o curso surtiram algum efeito na visão de ensino do processo de ensino e aprendizagem dos cursistas ou permitiram a esses organizar em algum grau as suas concepções sobre o processo. Essas informações poderiam servir de orientação para os formadores implementar melhorias e acertos nos cursos oferecidos.

Assim, dentro de certos limites, os modelos didáticos adotados como referenciais neste trabalho foram úteis para revelar concepções, indefinições e avanços de um grupo de professores, mostrando certa evolução no modelo didático pessoal, uma vez que parece haver uma crítica e talvez a superação do modelo de ensino tradicional, centrado no professor e na transmissão acrítica de conteúdos. 


\section{REFERÊNCIAS BIBLIOGRÁFICAS}

BRASIL. SECRETARIA DE EDUCAÇÃO MÉDIA E TECNOLÓGICA - Ministério da Educação e Cultura. Parâmetros Curriculares Nacionais do Ensino Médio. Brasília: MEC/SEMTEC, 1999.

. Diretrizes Curriculares Nacionais. Brasília: MEC/SEMTEC, 1999.

CHROBAK, R. Mapas conceituales y modelos didacticos de professors de química. In: Conference on Concept Mapping, 2, Congreso Internacional sobre Mapas Conceptuales, 2, 2006, San José, Costa Rica. Anais eletrônicos. San José: CMC, 2006, Sept. 5 - 8, 2006. Disponível em: <http://cmc.ihmc.us/cmc2006Papers/cmc2006-p215.pdf> Acesso em 09/02/2010.

ELBAZ, F. Teacher thinking: a study of practical knowledge. Londres: Croom Helm, 1983.

ROSA, Martín del Pozo; RIVERO GARCÍA, Ana \& PORLÁN ARIZA, Rafael. Conocimiento profesional y epistemología de los profesores, II: Estudios empíricos y conclusiones. Enseñanz̧a de las Ciencias, v. 16, n. 2, 1998, p. 271-288.

FURIÓ, C. Tendencias actuales en la formación del profesorado de ciências. Enseñanza de las Ciências, v. 12, n. 2, 1, 1994, p. 88-199.

GARCÍA PÉREZ, F.F. Los modelos didácticos como instrumento de análisis y de intervención en la realidad educativa. Revista Electrónica de la Universidad de Barcelona, Barcelona, n. 207. Disponível em: <http://www.ub.es/geocrit/b3w-207.htm> Acesso em: 20/05/2007.

GARCÍA, J. E. \& PORLÁN, R. Ensino de ciências e prática docente: uma teoria do conhecimento profissional. Caderno Pedagógico, Lajeado, n. 3, 2000, p. 7-42. Disponível em: <http://www.univates.br/files/files//univates_novo//editora/arquivos_pdf/caderno_pedagogico/caderno_pedagogico3/Ensinodecienciasepraticadocente.pdf> Acesso em: 09/02/2010.

GIL-PÉREZ, D.; CARVALHO, ANNA M. P. Formação de professores de Ciencias: tendências e inovações. São Paulo: Editora Cortez, 1995.

GUIMARÃES, M. A. G.; ECHEVERRÍA A. R. \& MORAES J. I. Modelos didáticos no discurso de professores de Ciencias. Revista Eletrônica de Investigação em Ensino de Ciências, Porto Alegre, v. 11, n. 3, 2006. Disponível em: http://www.if.ufrgs.br/ienci/artigos/Artigo_ID155/v11_n3_a2006.pdf Acesso em 02/02/2009.

HARRES, J. B. S.; PIZZATO, M. C.; HENZ, T. \& FONSECA, M. C. Evolução inicial das concepções didáticas de futuros professores de ciências exatas. Encontro de Pesquisadores em Ensino de Física, 9, 2004, Jaboticatubas (MG). Anais eletrônicos, Jaboticatubas: EPEF, 2004. Disponível em: $<$ http://miltonborba.org/CD/Interdisciplinaridade/Encontro_Gaucho_Ed_Matem/cientificos/CC41.pdf $>$. Acesso em: 09/02/2010.

JÍMENEZ, V. M. ¿Por quê a los profesores de Ciencias nos cuesta tanto cambiar nuestras concepciones y modelos didácticos? Revista Interuniversitaria de Formación del profesorado, n. 40, 2001, p. $17-$ 30. Disponível em: <http://www.aufop.com/aufop/uploaded_files/articulos/1223575368.pdf> Acesso em: 09/02/2010.

Cambio didáctico del profesorado de Ciencias experimentales y filosofia de la Ciencia. In: Enseñanza de las Ciencias, n. 21, v. 3, 2003, p. 343-358.

PEME-ARANEGA, C. Hacia la búsqueda de algunos fundamentos de decisiones educativas e investigastivas en didáctica de lãs ciencias: um aporte a la reflexión de los docentes de Biologia. Revista de Educacion en Biologia, v. 2, n. 1, 1999, p. 10-19.

Utilización del Inventario de Creencias Didácticas y Epistemológicas (ICDE) em la diferenciación de problaciones de docentes de ciências de nivel médio, de la ciudad de Córdoba. Comparación com um grupo de docentes de Biologia. Revista de Enseñanza de La Física, Córdoba, v. 2, n. 1, 2001, p. 15-24.

PÉREZ, R. J. \& AGUADO, A. M. W. ¿Es possibile el cambio em los modelos didácticos personales?: obstáculos em profesores de Ciencias Naturales de Educación Secundaria. Revista Interuniversitaria de Formación del profesorado. n. 46, 2003, p. 113-131. Disponível em: < http://redalyc.uaemex.mx/redalyc/pdf/274/27417108.pdf> Acesso em: 09/02/2010.

PORLÁN, R.; A. RIVERO Y. \& MARTÍN, R. Conocimiento profesional y epistemología de los profesores I: teoría, métodos e instrumentos. Enseñanza de las Ciencias, v. 15, n. 2, 1997, p. 155-171. 
. Conocimiento profesional y epistemología de los profesores, II: Estudios empíricos y conclusiones. Enseñanza de las Ciencias, Córdoba, v. 16, n. 2, 1998, p. 271-288.

SANTAELLA, C. M. Formación para la profesión docente. Revista Interuniversitaria de Formación del profesorado. n. 37, 2000, p. 171-186. Disponível em: <http://www.aufop.com/aufop/uploaded_files/articulos/1223463837.pdf> Acesso em 09/02/2010.

SANTOS Jr., J. B. Colaboração mediada como ferramenta na reestruturação do sistema de crenças pedagógicas sobre o ensino e aprendizagem do professor de Quimica. Dissertação de mestrado. USP, 2009. Disponível em: <http://www.if.usp.br/cpgi/DissertacoesPDF/Joao_Batista_dos_Santos_Jr.pdf> Acesso em: 09/03/2010.

SANTOS, W. L. P. \& MORTIMER, E. F. Tomada de decisão para a ação social responsável no ensino de Ciências. Ciência \& Educação, Bauru, v. 7, n. 1, p. 95-111, 2001. Disponível em: $<$ http://www2.fc.unesp.br/cienciaeeducacao/viewarticle.php?id=115\&layout=abstract $>$ Acesso em 09/02/2010.

SCHENETZLER, R. P. A pesquisa no ensino de Química e a importância da Quimica nova na escola. Revista Quimica Nova na Escola, n. 20, 2004, p. 49-54. Disponível em: $<$ http://qnesc.sbq.org.br/online/qnesc20/v20a09.pdf> Acesso em 09/02/2010. 
